\title{
ADVANCES IN BIOSORPTION OF HEAVY METALS
}

\author{
David Kratochvil and Bohumil Volesky \\ Department of Chemical Engineering \\ McGill University, 3610 University Str. \\ Montreal, Canada H3A 2B2 \\ e-mail address: boya@chemeng.LAN.mcgill.ca
}

\begin{abstract}
SUMMARY
Biosorption of heavy metals by various types of non-living (microbial) biomass appears as a very cost-effective new alternative for decontamination of metal bearing effluents. The understanding of metal biosorption mechanisms has progressed to the point where the process is being readied for scale up and field applications. Packed bed sorption columns is perhaps the most efficient equipment for this purpose. Process engineering aspects are examined for successful application of newly discovered biosorption materials which serve as natural and very efficient ion exchangers. Easy regeneration of biosorbents increases the process economy making it possible to reuse them in multiple sorption cycles. Optimization of the sorption/desorption cycles results in metal-free effluents and small volumes of highly concentrated metal desorbing solutions facilitating a conventional follow-up metal recovery.
\end{abstract}

\section{ADVANCES IN BIOSORPTION OF HEAVY METALS BRIEF DESCRIPTION OF BIOSORPTION TECHNOLOGY}

Biosorption is a process which utilizes inexpensive dead biomass to sequester toxic heavy metals. It is particularly feasible to use for removal of these contaminants from industrial effluents. Biosorbents are prepared from the naturally abundant and/or waste biomass of algae, moss, fungi, or bacteria which is inactivated and usually pretreated by washing with acids and/or bases before final drying and granulation (Brierley, 1990; Brierley et al., 1988; Fourest and Roux, 1994; Kratochvil et al., 1997). While simple cutting and/or grinding of the dry biomass may yield stable biosorbent particles (Brierley, 1990; Fourest and Roux, 1994; Kratochvil and Volesky, 1997; Kratochvil and Volesky, 1997; Kratochvil et al., 1997; Votapek et al., 1978), some types of biomass have to be to either immobilized in a synthetic polymer matrix (Greene and Bedell, 1990; Jeffers and Corwin, 1993) and/or grafted on an inorganic support material such as silica (Bedell and Darnall, 1990) in order to yield particles with the required mechanical properties (Mahan and Holcombe, 1992). The biosorbent particles can then be packed in sorption columns which are perhaps the most_effective device for the continuous removal of heavy metals. Biosorption columns operate on cycles which 
consist of loading, regeneration, and rinsing (Kratochvil and Volesky, 1997; Kratochvil and Volesky, 1997; Kratochvil and Volesky, 1997; Kratochvil et al., 1997). The operation commences by loading the sorbent material whereby a metal bearing effluent is passed through the packed-bed and the heavy metals are taken up from the liquid by the biosorbent. When the metal sorption capacity of the biosorbent is exhausted the column is taken out of operation. Its bed can then be regenerated with solutions of acids and/or hydroxides. The regeneration produces small volumes of heavy metal concentrates suitable for conventional metal recovery processes (Aldor et al., 1995; Brierley et al., 1986). The cycle ends with rinsing and/or backwashing of the bed with water to remove the remains of the regenerants and suspended solids captured in the column . In order to make the biosorption process truly continuous, pairs of columns are employed in parallel so that during the regeneration and rinsing of one of the columns the other is being loaded with heavy metals.

As compared to conventional methods for removing toxic metals from industrial effluents, such as precipitation with lime, ion exchange, and precipitation with biosulphide $\left(\mathrm{H}_{2} \mathrm{~S}\right.$ produced by sulfate-reducing bacteria), the biosorption process offers: 1 ) low operating cost; 2) minimization of the volume of chemical and/or biological sludge to be disposed of; 3) high efficiency in detoxification of very diluted effluents, and 4) no nutrient requirements. These advantages have served as the primary incentives for developing full-scale biosorption processes to clean up heavy metal pollution.

\section{ACHIEVEMENTS OVER THE PAST DECADE}

Although many biological materials bind heavy metals, only those with sufficiently high metal binding capacity and selectivity for heavy metals are suitable for use in a full-scale biosorption process. The first major challenge for the biosorption field was to select the most promising types of biomass from an extremely large pool of readily available and inexpensive biomaterials. While this task has not been completed, a good number of biomass types have been tested for metal binding capabilities under various conditions. Biomass of microbial origin has been of particular interest. The most complete summary of metal biosorption results has recently been presented (Volesky and Holan, 1995). The problem in comparing results from different sources is in widely variable ways of expressing the sorption capacity which need to be standardized. Table 1 lists some of the species which possess a metal binding capacity comparable to commercial synthetic cation exchange resins.

Although several proprietary biosorption processes were developed and commercialized early in this decade, such as AlgaSORB ${ }^{\mathrm{TM}}$, and AMT-Bioclaim ${ }^{\mathrm{TM}}$, a lack of better understanding of the mechanism underlying the metal sorption process has hindered adequate assessment of process performance and limitations and thus the expected wide-spread application of biosorption. Consequently, the selection of industrial effluents for pilot testing has remained largely intuitive as has the task of scaling up the process. The next real challenge for the field of biosorption was to identify the mechanism of metal uptake by dead biomass.

A few possible mechanisms of metal biosorption have been scrutinized (Crist et al., 1991), and several systematic studies of binding of heavy metals to particularly fungal and algal biomass have been undertaken (Fourest and Roux, 1994; Fourest et al., 1996; Schiewer, 1996). Simultaneously, research into interactions between purified 
biopolymers and heavy metals in solution, initiated earlier by Haug (Haug, 1961), and Muzzarelli (Muzzarelli, 1973), has been followed up on by Jang et al (Jang et al., 1995; Jang et al., 1995) and Jha (Jha et al., 1988). Although not all potentially applicable biosorbents have been systematically examined as yet, a substantial body of evidence has been collected which identifies ion exchange as the principal mechanism of metal biosorption. Moreover, strong links have been established between the metal sequestering by various types of biomass and metal binding by biopolymers extracted from the cells of the corresponding organisms (Macaskie and Dean, 1990).

\section{RECOGNITION OF ION EXCHANGE}

Since the early studies of the biosorption phenomenon, it has been known that the uptakes of heavy metal cations by most biomass types decrease dramatically as the $\mathrm{pH}$ of the metal solutions decreases from pH 6 to 2.5 (Greene et al., 1987, Guibal, 1992 \#945; Treen-Sears et al., 1984) as demonstrated in Figure 1. Since most of the heavy metals precipitate at $\mathrm{pH}>5.5$, it was initially contemplated that at higher $\mathrm{pH}$ values the metals may accumulate inside the cells, and/or the intrafibrillar capilarities of the cell walls by a combined sorption-microprecipitation mechanism (Beveridge, 1986). However, experiments performed in closed batch systems without $\mathrm{pH}$ adjustment revealed that the sorption of heavy metals onto acid washed biomass led to a decrease of the $\mathrm{pH}$ in the liquid (Crist et al., 1988). Based on these findings, a hypothesis of ion exchange between protons and heavy metals was formulated. A study which followed revealed that fungal biomass pretreated with solutions of $\mathrm{Ca}^{2+}$ and $\mathrm{Na}^{2+}$ released cations of these two light metals into the solution while sorbing $\mathrm{Zn}^{2+}$ and $\mathrm{Pb}^{2+}$ (Fourest and Roux, 1994). Moreover, the respective quantities of the heavy metals taken up by the fungal biomass and of the light metals released into the liquid were shown to be approximately equal. Similar results were obtained with fresh water algae (Crist et al., 1994), and seaweed biomass (Crist et al., 1992; Kratochvil et al., 1995). It is now well established that heavy metals are taken up from water predominantly in exchange for counterions present in the biomass.

The typical dependence of metal uptake on $\mathrm{pH}$ shown in Figure 1 pointed to the weakly acidic carboxyl groups R-COOH ( $\mathrm{pK}_{\mathrm{a}}$ from the interval of 3.5 - 5.5) of algal and fungal cell wall constituents as the probable sites of ion exchange. As early as 1979, the behavior of acid washed peat was described as being similar to that of polycarboxylic acid (Bloom and McBride, 1979). The significant role of R-COOH groups of peptidoglycan in metal sequestering by gram-positive bacteria was also pointed out (Beveridge, 1986). Conductometric and potentiometric titrations with seaweed biomass of Sargassum fluitans revealed the weakly acidic character of the metal binding sites in this brown marine alga (Fourest et al., 1996; Fourest and Volesky, 1996). This work demonstrated that a good correlation existed between the degree of blocking of - $\mathrm{COOH}$ groups via esterification in fungal and seaweed biomass and the corresponding decrease in metal uptake by these biomass types. Similar results were obtained by others who carried out esterifications of carboxyl groups in the biomass of the fresh water algae of Chlorella vulgaris (Cho et al., 1994), and Chlorella pyrenoidosa and Cyanidium caldarium (Gardea-Torresdey et al., 1990), respectively. The contribution of other functional groups present in the cells and the cell walls of algae and fungi, such as the strongly acidic sulfate groups $\mathrm{R}^{-\mathrm{OSO}^{-}}$of fucoidan and carrageenan, and the amino 
groups of chitin $\mathrm{R}_{2}-\mathrm{NH}$ and chitosan $\mathrm{R}-\mathrm{NH}_{2}$, was also subject to examinations. The presence of the former was detected in algae Sargassum (Fourest and Volesky, 1996) and

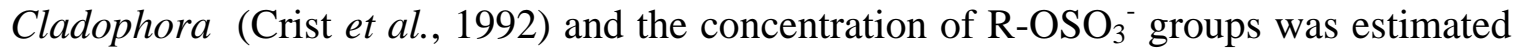
to range from 0.2 to $0.3 \mathrm{meq} / \mathrm{g}$. This represented approximately $10 \%$ of the overall metal binding sites of these seaweeds. The importance of the sulfate ester groups for the biosorption of heavy metals by seaweed biomass is likely to further decrease after several washes with acids, since it is known that the sulfated polysaccharides are prone to digestion via hydrolysis under acidic conditions (Percival and McDowell, 1967). As far as the amino groups are concerned, Muzzarelli (Muzzarelli, 1973) and Jha (Jha et al., 1988) demonstrated that the ion exchange between protons and metals on these groups is characterized by a $\mathrm{pH}$ dependence similar to that observed for carboxyl groups. However, the $\mathrm{pH}$ value at which the metal uptake sharply increases and reaches its maximum is generally higher for the amino groups than for the carboxyl groups. Moreover, a comparison between the maximum metal uptakes of fungal biomasses studied (Muraleedharan and Venkobachar, 1990; Tsezos and Volesky, 1981) and those obtained for pure chitin and chitosan (Jha et al., 1988; Tsezos, 1980) revealed that the binding by chitin and chitosan can account for only approximately $10 \%$ of the overall binding capacity of these fungi.

In light of these recent results, biosorbents can be viewed as natural ion exchange materials which contain primarily weakly acidic and weakly basic functions. It follows from the theory of acid-base equilibrium that in the range of $\mathrm{pH}$ of 2.5-5 that the binding of heavy metal cations is determined primarily by the state of dissociation of the weakly acidic groups. Furthermore, since the much publicized selectivity of synthetic resins such as IRC50 and IRC718 for heavy metals has been attributed to the presence of carboxyl groups in their synthetic matrix (Anonymous, 1989; Anonymous, 1989), the natural selectivity of biosorbents which was often observed, but hitherto never explained, can now be comprehended. Finally, the well developed and structured knowledge of ion exchange can now be applied to biosorption. This gives researchers and engineers who work with biosorbents new tools for studying, developing, and application of the biosorption process.

\section{EVALUATION OF EQUILIBRIUM BINDING OF METALS}

Biosorption process involves a solid phase (sorbent) and a liquid phase (solvent, normally water) containing a dissolved species to be sorbed (sorbate, e.g. metal ions). Due to the higher 'affinity' of the sorbent for the sorbate species the latter is attracted into the solid and bound there by different mechanisms. This process takes place until an equilibrium is established between the amount of solid-bound sorbate species and its portion remaining in solution (at a residual, final or equilibrium concentration $\boldsymbol{C}_{f}$ ). The degree of the sorbent 'affinity' for the sorbate determines its distribution between the solid and liquid phases.

The quality of the sorbent material is judged according to how much sorbate it can attract and retain in an 'immobilized' form. The determination of the metal uptake $(\boldsymbol{q})$ by the biosorbent is most often based on the material balance of the sorption system: sorbate which 'disappeared' from the solution must be in the solid. The sorption uptake $\boldsymbol{q}$ can be expressed in different units depending on the purpose of the exercise: 
e.g. mg of metal sorbed per gram of the (dry) sorbent material (basis for engineering process mass balance calculations), $\mathbf{m m o l} / \mathbf{g}$ or mequiv/g (used when stoichiometry and/or mechanism is considered). For (bio)sorption process scale-up and applications the uptake expressed per unit (reactor) volume is important.

\section{Comparison of Sorption Performance}

Which sorbent is 'better' ? There is no direct answer to that until this question is qualified: at which residual concentration? The metal uptake of two biosorbents must be compared only at the same equilibrium concentration. This is the reason why one comparison at "low" $\boldsymbol{C}_{\boldsymbol{f}}$ (e.g. $10 \mathrm{mg} / \mathrm{L}$ ) and also another one at "high" $\boldsymbol{C}_{\boldsymbol{f}}$ (e.g. $\left.200 \mathrm{mg} / \mathrm{L}\right)$ was made in some biosorption screening work (Figure 2) (Holan and Volesky, 1994; Holan et al., 1993). The comparison of single-sorbate sorption performance is best based on a complete single-sorbate sorption isotherm curves derived under the same environmental conditions (e.g. pH, temperature, ionic strength, etc.).

Sorption isotherms are plots between the sorption uptake $(\boldsymbol{q})$ and the final equilibrium concentration of the residual sorbate remaining in the solution $\left(\boldsymbol{C}_{\boldsymbol{f}}\right)$. Classical models of Langmuir (Langmuir, 1918) and Freundlich (Freundlich, 1907) are often used to describe the relationship.

$$
\begin{array}{ll}
\text { Langmuir: } & q=q_{\max } \frac{b C_{f}}{1+b C_{f}} \\
\text { Freundlich: } & q=K C_{f}^{1 / n}
\end{array}
$$

It is important to note the assumptions for these models which originated from the work done with activated carbon. Ion exchange process apparently plays an important role in biosorption and this is reflected in appropriately different equilibrium models proposed for biosorption based on ion exchange principles (Schiewer, 1996; Schiewer and Volesky, 1995; Schiewer and Volesky, 1996; Schiewer and Volesky, 1997; Schiewer and Volesky, 1997).

A steep initial slope of a sorption isotherm indicates a sorbent which has a high capacity for the sorbate in the low residual (final, $\boldsymbol{C}_{f}$ ) concentration range (high affinity). This affinity is indicated by the coefficient $\boldsymbol{b}$ in the Langmuir equation which is often conveniently fitted to experimental sorption results although it does not correspond to the biosorption (ion exchange) phenomena. The lower the value of langmuirian $\boldsymbol{b}$ the higher the affinity. In conclusion, for 'good' sorbents in general, one is looking for a high $\boldsymbol{q}_{\max }$ and a steep initial sorption isotherm slope as indicated by e.g. low values of Langmuir parameter $\boldsymbol{b}$.

It is relatively simple and easy to obtain laboratory equilibrium sorption data for a single sorbate. A small amount of the sorbent tested is brought into contact with solution containing the given sorbate. However, the 'environmental' parameters in the sorption system (particularly $\mathrm{pH}$ ) may have to be carefully controlled unless an appropriate (ion exchange) sorption model is available to compensate for the changing proton concentration in the system (Schiewer and Volesky, 1995; Schiewer and Volesky, 1997). Otherwise, the $\mathrm{pH}$ control has to be implemented over the entire period of contact until the sorption equilibrium is reached. It may take a few hours or much longer depending on the size of sorption particles and the time it takes until they attain sorption 
equilibrium. A simple preliminary sorption kinetics test will establish the exposure time necessary for the given sorbent particles to reach the equilibrium state characterized by the unchanging sorbate concentration in the solution. That is determined by time-based analyses.

Safely 'enough' time has to be allowed for the sorption system to reach equilibrium. Note that $\boldsymbol{q}$ could also be determined directly by analyzing the separated solids and thus closing the material balance on the sorbate in the system. However, this usually presents analytical difficulties (digestion-liquefaction of solids and/or very sophisticated analytical methods may be required). From the equilibrium principles it is easily seen that the initial concentration of sorbate $\left(\boldsymbol{C}_{i}\right)$ is of little relevance in the batch sorption equilibrium tests. It can assist in identifying the final concentration range which, of course, depends on the amount of sorbent solids $(\boldsymbol{S})$ in the system. Also note that one has very little control over the value of $\boldsymbol{C}_{f}$, it sort of "happens" during the experiment.

The comparison of sorbents based on "\% Removal" is often encountered in the literature. However, it is so approximate that it could lead to outright misleading conclusions on the relative sorption performance. It can only serve the purpose of crude orientation, perhaps adequate only for quick and very approximate screening of (bio)sorbent materials.

\section{EVALUATION OF TWO-METAL EQUILIBRIUM BIOSORPTION}

Very often the case occurs when there is more than one metal in the solution and the assessment of the sorption performance becomes more complicated. First, the case of two metals will be examined. Bear in mind that the 'second sorbate' may represent a whole group of metals (or even other materials) represented as an additional general 'second ion' whose interference with the uptake of the primary one is to be assessed.

Graphically, this case can be represented by adding another concentration axis to the conventional sorption isotherm plot. The isotherm curve will become a 3-dimensional "sorption isotherm surface". However, since there is no control over the experimentally derived values of the equilibrium concentration $\left(C_{f}\right)$ in the sorption system, processing and evaluation of the two-metal experimental equilibrium data becomes more involved. The approach, pioneered by Chong and Volesky (Chong and Volesky, 1995) has been well illustrated recently (Figueira et al., 1997).

Since all the $C_{f}$ and corresponding $q$ values belong to the same "isotherm surface" (Figure 3a) it can be 'cut' by selected "iso-concentration" parallel planes at chosen "second-metal" $C_{f}$ 's yielding in projection a series of isotherms for the first metal as affected by the (increasing) presence of the second metal (Figure 3b). Eventually, a summary of the effect of the second metal on the sorption of the first one, at its chosen specific uptake level (the ${ }^{\boldsymbol{1}} \boldsymbol{q}_{\max }$ or any other agreed-upon ${ }^{\boldsymbol{1}} \boldsymbol{q}$ level, e.g. ${ }^{\boldsymbol{1}} \boldsymbol{q}_{10}$ or ${ }^{\boldsymbol{1}} \boldsymbol{q}_{200}$ ), can be constructed from these isotherms seen in Figure 3c.

According to the q uptake calculated and used there could be 3 different sorption isotherm surface plots:

- for the uptake of Metal 1: yielding the effect of Metal 2 on Metal 1 (Figure 3);

- for the uptake of Metal 2: yielding the effect of Metal 1 on Metal 2; and

- for the total uptake (M1 + M2 uptake). 
Since the experimental points for the surface are likely to exhibit a certain degree of scattering, there would have to be an algorithm found to 'smooth' the experimental surface just like an experimental curve is often smoothed to compensate for experimental errors of individual data points. To do this in a 3-D just requires more calculating power nowadays easily available by using a computer which can also fit a suitable mathematical model to the surface. The availability of a mathematical model is essential for the surface 'cutting' exercise. Plotting of the surface could even be omitted and kept only as a 'background' exercise and only the resulting cuts or their overall summary is then presented.

\section{Ion-Exchange Isotherms}

Recent research work has indicated that ion exchange may be the predominant metal ion binding mechanism in biosorption (Crist et al., 1990; Fourest and Roux, 1994; Kratochvil et al., 1995; Spinti et al., 1995). The classical ion exchange concept based on exchange equilibrium constants and separation factors (Shallcross et al., 1988; Vermeulen et al., 1973) can be applied to this case. For a more generalized ion exchange reaction:

$$
\mathrm{bA}^{+\mathrm{a}}+\mathrm{aB} \underline{\mathrm{B}}^{+\mathrm{b}} \Leftrightarrow \mathrm{b} \underline{\mathrm{A}}^{+\mathrm{a}}+\mathrm{aB} \mathrm{B}^{+\mathrm{b}}
$$

the equilibrium constant $K_{A B}$ and the separation factor $r_{A B}$ are defined in equations (4a) and (4b), respectively, for the case of ideal behavior of the exchanging species in both of the phases:

$$
\begin{aligned}
K_{A B} & =\frac{q_{A}^{b} C_{B f}^{a}}{C_{A f}^{b} q_{B}^{a}}=\left(\frac{y_{A}^{b} x_{B}^{a}}{x_{A}^{b} y_{B}^{a}}\right) \frac{C_{0}^{a-b}}{Q^{a-b}} \\
r_{A B} & =\frac{y_{A} x_{B}}{x_{A} y_{B}}
\end{aligned}
$$

For the binary ion exchange system, the value of the equilibrium constant $K_{A B}$ can be determined from the slope of the plot of $\frac{q_{A}}{q_{B}}$ versus $\frac{C_{A}}{C_{B}}$. The ion exchange isotherms are usually displayed using dimensionless forms of the uptake and concentration and they vary in shape depending on the total normality of the solution (Selke, 1956):

$$
\frac{q_{M}}{Q}=f\left(\frac{C_{M L}}{C_{0}}\right)
$$

The overall binding capacity $\mathrm{Q}$ (meq/g of dry biosorbent) for e.g. a binary sorption system is given by the sum of the functional groups in the sorbent:

$$
Q=q_{A}+q_{B}
$$

The total normality of the solution $C_{0}$ is given by:

$$
C_{0}=C_{A}+C_{B}
$$

Similar to ion exchange resins, biosorbents can also be prepared in different ionic forms such as H-form and Ca-form (Kratochvil et al., 1997) and the sorption analysis is often reduced to considering a series of simple binary ion exchange systems. By 
eliminating $q_{B}$ through substitutions (Kratochvil et al., 1997) a useful expression for $\frac{q_{A}}{Q}$ can be obtained:

$$
\begin{aligned}
& \frac{q_{A}}{Q}=\frac{1}{1+\frac{C_{B}}{K_{A B} C_{A}}}=\frac{1}{1+\bar{k} C_{B}} \\
& \text { where } \bar{k}=\frac{1}{K_{A B} C_{A}}
\end{aligned}
$$

Since $\frac{q_{A}}{Q}$ represents the fraction of the binding sites occupied by A, equation (8) may be used to evaluate the decrease of the equilibrium uptake of the species A by the biosorbent due to the presence of species B. Equation (8) shows that when $C_{B}=0, \frac{q_{A}}{Q} \cong 1$, regardless of the absolute value of the final concentration of $\mathrm{A}, C_{A}$. This distinguishes ion exchange from chemisorption and/or physical sorption known to occur on activated carbon. Furthermore, equation (8) shows that for a fixed value of $C_{A}$, the $\frac{q_{A}}{Q}$ is a hyperbolic function of $C_{B}$ and it may also be transcribed using simple dimensionless concentration fractions as variables:

$$
x_{A}=\frac{C_{A}}{C_{0}} ; \quad x_{B}=\frac{C_{B}}{C_{0}} ; \quad y_{A}=\frac{q_{A}}{Q}
$$

yielding equation (10) which represents an ion exchange isotherm for a binary sorption system:

$$
y_{A}=\frac{1}{1+\frac{x_{B}}{K_{A B} X_{A}}}
$$

Since $y_{A}, x_{B}$, and $K_{A B}$ are all dimensionless, equation (10) represents the most generalized description of the ion exchange sorption equilibrium for binary systems (Figure 4).

\section{OPERATION OF BIOSORPTION COLUMNS}

\section{A) Effect of the ionic form of biosorbent on metal removal}

The recent studies of biosorption phenomenon revealed that biosorbents, very much like synthetic ion exchange resins, can be prepared in different ionic forms, i.e. protonated (H-form), or saturated with $\mathrm{Ca}, \mathrm{Mg}$ or $\mathrm{Na}$, etc., by washing the biomass with mineral acids, salts and/or bases. Consequently, questions arise as to what ionic form should be used for removing heavy metals, and what chemicals should be selected for desorbing the metals, in order to assure the optimal performance of the biosorption columns.

The overall performance of flow-through columns is very much related to the length and shape of the ion exchange zone which develops in a column during sorption 
and regeneration as shown in Figure 5. The ion exchange zone develops between the section of the column which is saturated with heavy metal(s) and the section which contains still fresh biosorbent. As the loading or regeneration of the biosorbent progresses, the zone moves along (usually down) the column in the direction of the liquid flow . Clearly, the shorter the zone, the longer the service time of the column during the loading stage. Correspondingly, also the more complete the desorption of metals from biosorbents during the regeneration stage. For the case of a species A sorbing onto Bsaturated biosorbent, the theory of ion exchange distinguishes between two different scenarios of column performance depending on the respective affinities of $\mathrm{A}$ and $\mathrm{B}$ towards the sorbent material. These two scenarios are reflected in the shapes of the breakthrough curves resulting from such column operations as shown in Figure 6. If species $\mathrm{A}$ is more strongly bound to the resin than species $\mathrm{B}$, i.e. the affinity of $\mathrm{A}>\mathrm{B}$, then the zone which develops in a column is short and retains its shape as it moves down the column. However, if the affinity of $B$ is greater than that of $A$, the zone extends across a large section of the column, and is prone to further broadening as the operation progresses. This indicates that a high degree of biosorbent utilization or regeneration is achieved only if the species sorbing onto a biosorbent has a higher affinity than the species originally present in the sorbent. Therefore, the selection of 1 ) the ionic form of the biosorbent for the loading stage, and 2) the regenerant for the regeneration stage, should assure that at least one, but ideally both of these stages, would follow the pattern of strongly binding A replacing weakly bound B.

Since biosorption is a process whereby the toxic heavy metals are removed in exchange for non-toxic species, the relative positions of protons, heavy metals, and light metals in the affinity series determine the suitability of the ionic forms and regenerants. Unfortunately, at the present time, most of the affinity series reported for different biosorbents in the literature include only heavy metals. Therefore, one of the priorities of future research should be to establish complete series of affinities including heavy metals, light metals and protons for selected biosorbents.

\section{B) Selecting ionic forms for carboxyl groups}

Carboxyl groups are known for their high selectivity for protons. Consequently, small volumes of diluted mineral acids usually yield a complete desorption of heavy metals from biosorbents (Aldor et al., 1995). However, there is a disadvantage to using acid washed biomass for the loading stage since the metals with low affinities to the carboxyl groups cannot displace the strongly bound protons from the H-saturated biomass. Therefore, a partial and/or a complete neutralization of these groups may be required prior to loading in order to achieve an effective sorption removal of some heavy metals. Fourest (1994) observed that by converting the R. arrhizus biomass from $\mathrm{H}-$ to $\mathrm{Na}$ - and/or $\mathrm{Ca} / \mathrm{Mg}$-forms by washing the biosorbent with a solution of $\mathrm{NaHCO}_{3}$, and hard water, respectively, the capacity of the biosorption column more than tripled. Similarly, others (Jeffers et al., 1991; Trujillo et al., 1991) used a solution of $\mathrm{NaHCO}_{3}$ to regenerate peat moss biomass immobilized in polysulfone beads after the desorption of metals with acids. While Na-forms of fungal and immobilized peat biomass appeared stable, Na-alginate is leached from seaweed biomass such as Ascophyllum nodosum and Sargassum fluitans. In fact since alginate is one of the main constituents of the cell walls in brown algae, its solubilization may lead to a disintegration of the entire cellular 
structure of the seaweed. Hence, Na- and K- forms of seaweed biosorbents are not stable, and $\mathrm{H}$ - or Ca-form are recommended instead for the removal of heavy metals from water containing low, and high concentrations of metals, respectively (Kratochvil et al., 1997).

\section{C) Effect of wastewater composition}

The feasibility and efficiency of a biosorption process depends not only on the properties of the biosorbents, but also on the composition of the wastewater. The faith in emerging technologies in wastewater treatment much too often hinges on the success of pilot tests carried out with a specific industrial effluent. It is particularly important that only effluents which can be treated efficiently are selected for extended testing of the biosorption process. This aspect has not been considered carefully enough and in the rush toward the applications of biosorption purification of industrial effluents is examined most often without appropriate knowledge of the biosorption process. The following paragraph discusses some of the limits and/or potential risks which may be imposed on a biosorption process by the composition of the wastewater.

A majority of industrial effluents contain more than one toxic heavy metal. Consequently, biosorption in columns involves competitive ion exchange whereby several toxic heavy metals compete for a limited number of binding sites on a biosorbent. In practical applications, the loading of biosorption columns has to be terminated as soon as the concentration of one of the toxic species in the column effluent exceeds the regulation limit. It is well known from the theory and practice of ion exchange that the species which first breaks through the column is the one with the lowest affinity towards the resin. Hence the service time of biosorption columns is determined by the toxic metal with the lowest affinity present in the feed.

The service time of biosorption columns can be reduced if the industrial effluent contains a non-toxic species interfering with the sorption of the toxic metals. The variety of ionic species of ferrous and ferric iron represent a particular concern for a biosorption process treating mining effluents. While the cations of $\mathrm{Fe}^{2+}$ can potentially compete with cations of toxic metals for the binding sites in the biomass, Fe(III) is usually present in the from of suspended solids (SS). This is the reason why careful evaluation of the applicability of a biosorption process for treating mining effluents is required. The selectivity of biosorbents for toxic metals over $\mathrm{Fe}^{2+}$ should be established. Furthermore, the effect of the level of SS in the feed on the column performance should be examined.

A special class of heavy metal pollution is represented by effluents containing one toxic species at a relatively high level in combination with one or more heavy metals at levels which may not be considered toxic. Typical examples may be diluted electroplating effluents originating from a spent $\mathrm{Zn}$ bath containing traces of $\mathrm{Cu}$ and $\mathrm{Al}$, or effluents produced at a copper mine containing a high level of $\mathrm{Cu}$ and traces of $\mathrm{Cd}, \mathrm{Ni}$, and/or Mn. Usually, only the toxic metal with the high concentration is targeted for removal, and thus it is expected that the affinity and the concentration of this metal will determine the efficiency of the biosorption process. However, due to the competitive ion exchange taking place in the column, one or more of the metals present at trace levels may overshoot the acceptable limit in the column effluent well before the breakthrough point of the targeted metal, thereby reducing the service time of the column considerably. This is shown schematically in Figure 7a. However, Figure 7b illustrates that not all overshoots necessarily lead to the reduction of the column service time. While output 
concentration overshoots have been observed experimentally (Costa et al., 1996; Kratochvil and Volesky, 1997; Trujillo et al., 1991), until recently (Kratochvil and Volesky, 1998) their occurrence and impact on heavy metal removal has not been discussed, analyzed, or even considered.

\section{MODELS ASSISTING IN PROCESS DEVELOPMENT}

Models play a key role in transferring technologies from the laboratory to a full scale application. Good models can help not only in analyzing and interpreting experimental data, but also in predicting the response of the systems to changing conditions. Analysis of a biosorption column performance has been attempted by means of the conventional Bohart-Adams sorption model (Jansson-Charrier et al., 1996; Muraleedharan et al., 1994; Volesky and Prasetyo, 1994). This model was developed for sorption on Granulated Activated Carbon (GAC) (Bohart and Adams, 1920), and it assumes that the adsorption rate is proportional to both the residual capacity of the GAC and the concentration of the sorbing species. The performance of pilot scale columns is analyzed by plotting service time versus bed depth for several different flow rates and column lengths. Although the model provides a simple and comprehensive approach to running and evaluating pilot scale tests, its validity is limited to the range of conditions used during the pilot tests (Faust and Aly, 1987). Furthermore, the model assumes the presence of only one contaminant in the wastewater. Finally, the fundamental difference between ion exchange and sorption on the GAC effectively limit the use of this model in biosorption. For example, the Bohart-Adams model cannot predict the important effects on column performance of changes in $\mathrm{pH}$, ionic forms of the biosorbent, feed composition, and feed normality. For all of the above reasons, the Bohart-Adams model should not be used for interpreting results obtained from laboratory scale biosorption columns. Nevertheless, the methodology of pilot tests, and the pilot data evaluation, remains instructive for sizing biosorption columns (Volesky and Prasetyo, 1994).

Klein (Klein et al., 1967), Tondeur et al. (Tondeur and Klein, 1967), and Helfferich (Helfferich, 1967) developed the Equilibrium Column Model (ECM) for a quick assessment of multicomponent ion exchange processes in columns. The ECM can predict the minimum usage rate of a resin/biosorbent in [ $\mathrm{kg}$ of biosorbent / $\mathrm{L}$ of water treated), the elution order of ions from a column, the occurrence of effluent concentration overshoots, and the maximum overshoot concentrations at the column outlet. The ECM assumes a negligible mass transfer resistance for ions diffusing in and out of sorbents, a premise which is never true in real sorption columns. Therefore, this model cannot predict the exact service time of the column. Nevertheless, the ECM is useful since it is not limited to single component systems, requires only the knowledge of equilibrium constants for the species involved, and is simple to use. Therefore, the ECM is likely to be used at a preliminary stage of selecting a biosorbent for a specific effluent where the biosorbent usage rate, the occurrence, and the potential risks of concentration overshoots can be quickly evaluated.

The most complete column model which includes the mass transfer limitations was developed for ion exchange by Tan and Spinner (Tan and Spinner, 1994). In principle, this model can predict breakthrough curves for all of the species being removed by the biosorbent as well as the elution curves obtained during regeneration (Kratochvil and Volesky, 1997; Kratochvil and Volesky, 1998). However, in order to solve the 
model equations, a special computer code is necessary. Moreover, a knowledge of the values of mass transfer coefficients for all of the ionic species in the system is required. The values of these coefficients can be estimated, specifically derived (Yang and Volesky, 1996) or determined by fitting the model to experimental data. The major advantage of the model is that it can simulate and predict the performance of a column under various conditions including different flowrates, compositions of the feed, column sizes, porosities of the bed, and ionic forms of the biosorbent. Therefore, this model can assist engineers to scale up the biosorption process by 1 ) selecting the conditions under which to run pilot tests, and 2) simulating the performance of the final design based on the results of these tests.

\section{BIOSORPTION OF HEAVY METAL ANIONS}

While a larger portion of current research has been oriented towards the removal of heavy metal cations, the uptake of anions by biomass has become a growing concern in the field of biosorption. The removal of molybdate $\left(\mathrm{MoO}_{4}{ }^{2-}\right)$ by chitosan beads has recently been studied (Milot et al., 1997). The uptake of molybdate as high as $700 \mathrm{mg} / \mathrm{g}$ was reported. In order to avoid the dissolution of the beads under acidic conditions, the chitosan was partially crosslinked with glutaraldehyde. Removal of hexavalent chromium Cr(VI) by peat moss (Sharma and Forster, 1993), corn cobs (Bosinco et al., 1996), and seaweed biomass (Kratochvil and Volesky, 1998) has been studied with promising results. The optimum $\mathrm{pH}$ for $\mathrm{Cr}(\mathrm{VI})$ removal by all of these biomasses was reported to lie in the interval of $\mathrm{pH} 1.5$ to 2.5. Moreover, the studies revealed that while some $\mathrm{Cr}(\mathrm{VI})$ was taken up by the biomass, considerable quantities of $\mathrm{Cr}(\mathrm{VI})$ were reduced to Cr(III). Sharma and Foster (1993) and Kratochvil et al. (1998), proposed an anion exchange mechanism for the sorption of $\mathrm{Cr}(\mathrm{VI})$ whereby the protonated weakly basic groups in the biomass take up $\mathrm{HCrO}^{-}$ions from solution in exchange for $\mathrm{OH}^{-}$. The reduction of $\mathrm{Cr}(\mathrm{VI})$ to $\mathrm{Cr}(\mathrm{III})$ at low $\mathrm{pH}$ was attributed to the effect of $\mathrm{pH}$ on the value of the reduction potential of the $\mathrm{HCrO}_{4}{ }^{-} / \mathrm{Cr}^{3+}$ couple (Kratochvil and Volesky, 1998 ). However, more research is needed to 1 ) ascertain the proposed mechanisms and 2) to develop mathematical models for the sorption of anions. Since some highly toxic metals occur in anionic forms (As, Se, Cr, Mo, Va, etc.), studies of anion biosorption remain an open and relevant challenge.

\section{NOMENCLATURE}

a, b stoichiometric coefficients in the ion exchange reaction equation (3)

$\underline{A}, \underline{B} \quad$ species in the solid sorbent phase

A, B species in the liquid

$b \quad$ constant in the Langmuir model related to affinity

$C_{0} \quad$ normality of the solution $[\mathrm{meq} / \mathrm{L}]$

$C_{M}=x_{M} \quad$ equivalent fraction of species $\mathrm{M}$ in liquid phase

$C_{M}$

$C_{M f}$

$C_{M L}$ equilibrium concentration of species $\mathrm{M}$ in liquid phase [mmol/L] equilibrium final concentration of species $\mathrm{M}$ in liquid phase [mmol/L] concentration of species $\mathrm{M}$ in liquid phase $[\mathrm{mmol} / \mathrm{L}]$ 


$\begin{array}{ll}\bar{k} & \text { constant defined in equation (8) } \\ K & \text { constant in the Freundlich sorption isotherm model } \\ K_{A B} & \text { ion exchange equilibrium constant } \\ n & \text { constant in the Freundlich sorption isotherm model } \\ q, q_{A}, q_{B} & \text { sorption uptake, and uptake of species A or B [mmol/g] } \\ q_{\max } & \text { maximum sorbate uptake } \\ Q & \text { equilibrium uptake of } \mathrm{M} \text { at } C_{M L}=C_{M} 0 . C_{0} \text { [meq/g] } \\ r_{A B} & \text { ion exchange separation factor } \\ x_{A}, x_{B} \text { equivalent fractions of species A and B, respectively, in liquid phase } \\ y_{A}, y_{M} \quad \text { equivalent fractions of species A and M, respectively, in solid phase }\end{array}$

\section{REFERENCES}

Aldor, I., Fourest, E. and Volesky, B. (1995). Can. J. Chem. Eng. 73, 516-522. Anonymous (1989). Amberlite IRC-718, Philadelphia, PA: Rohm and Haas Co., Inc. Anonymous (1989). Amberlite IRC-50, Philadelphia, PA: Rohm and Haas Co., Inc.

Bedell, G.W. and Darnall, D.W. (1990). Immobilization of nonviable, biosorbent, algal biomass for the recovery of metal ions. In: Biosorption of Heavy Metals, B. Volesky, ed. pp. 313-326, Boca Raton, FL: CRC Press.

Beveridge, T. J. (1986). The immobilization of soluble metals by bacterial walls. In: Biotechnology and Bioengineering Symposium No. 16: Biotechnology for the Mining, Metal-Refining, and Fossil Fuel Processing Industries, H.L. Ehrlich and D.S. Holmes, eds. pp. 127-140, New York, NY: J. Wiley Interscience.

Bloom, P. R. and McBride, M. B. (1979). Soil. Sci. Soc. Am. 43, 687-692.

Bohart, G. S. and Adams, E. Q. (1920). J. Am. Chem. Soc. 42, 523-544.

Bosinco, S., Roussy, J., Guibal, E. and LeCloirec, P. (1996). Environ.Technol. 17, 55-62. Brierley, J.A. (1990). Production and application of a Bacillus-based product for use in metals biosorption. In: Biosorption of Heavy Metals, B. Volesky, ed. pp. 305312, Boca Raton, FL: CRC Press.

Brierley, J.A., Brierley, C.L., Decker, R.F. and Goyak, G.M. (1988). U.S. Patent 4789481.

Brierley, J.A., Brierley, C.L. and Goyak, G.M. (1986). AMT-BIOCLAIM: A new wastewater treatment and metal recovery technology. In: Fundamental and Applied Biohydrometallurgy, R.W. Lawrence, R.M.R. Branion and H.G. Ebner, eds. pp. 291-304, Amsterdam, The Netherlands: Elsevier.

Cho, D. Y., Lee, S. T., Park, S. W. and Chung, A. S. (1994). J. Envir. Sci. Health, A: Envir. Sci. Eng. 29, 389-409.

Chong, K. H. and Volesky, B. (1995). Biotechnol. Bioeng. 47, 451-460.

Costa, A. C. A., Mesquita L.M.S. and Tosovsky, J. (1996). Minerals Engineering. 9, 811-824.

Crist, R. H., Martin, J. R., Carr, D., Watson, J. R., Clarke, H. J. and Crist, D. R. (1994). Environ. Sci. Technol. 28, 1859-1866.

Crist, R.H., Martin, J.R. and Crist, D.R. (1991). Interaction of metals and protons with algae. Equilibrium constants and ionic mechanisms for heavy metal removal as 
sulfides and hydroxides. In: Mineral Bioprocessing, R.W. Smith and M.Misra, eds. pp. 275-287, The Minerals, Metals and Materials Society, Washington, DC.

Crist, R.H., Martin, J.R., Guptill, P.W., Eslinger, J.M. and Crist, D.R. (1990). Environ. Sci. Technol. 24, 337-342.

Crist, R. H., Oberholser, K., McGarrity, J., Crist, D. R., Johnson, J. K. and Brittsan, J. M. (1992). Environ. Sci. Technol. 26, 496-502.

Crist, R. H., Oberholser, K., Schwartz, D., Marzoff, J., Ryder, D. and Crist, D. R. (1988). Environ. Sci. Technol. 22, 755-760.

Faust, S.D. and Aly, O.M. (1987). Adsorption Processes for Water Treatment, Stoneham, UK: Butterworths Publishers.

Figueira, M.M., Volesky, B. and Ciminelli, V.S.T. (1997). Biotechnol. Bioeng. 54, 344-350.

Fourest, E. and Roux, J.-C. (1994). FEMS Microbiol. Rev. 14, 325-332.

Fourest, E., Serre, A. and Roux, J.-C. (1996). Toxicol. Environ. Chem. 54, 1-10.

Fourest, E. and Volesky, B. (1996). Environ. Sci. Technol. 30, 277-282.

Freundlich, H. (1907). Z. physik. Chem. 57, 385-470.

Gardea-Torresdey, J.L., Becker-Hapak, M.K., Hosea, J.M. and Darnall, D.W. (1990). Environ. Sci. Technol. 24, 1372-1378.

Greene, B. and Bedell, G.W. (1990). Algal gels or immobilized algae for metal recovery. In: An Introduction to Applied Phycology, I. Akatsuka, ed. pp. Amsterdam, The Netherlands: SPB Academic Publ.

Greene, B., McPherson, R. and Darnall, D. (1987). Algal sorbents for selective metal ion recovery. In: Metals Speciation, Separation and Recovery, J.W. Patterson and R. Pasino, eds. pp. 315-338, Chelsea, MI: Lewis.

Haug, A. (1961). Acta Chem. Scand. 15, 1794-1795.

Helfferich, F. G. (1967). Ind. Eng. Chem. Fundam. 6, 362-364, 424-426.

Holan, Z. R. and Volesky, B. (1994). Biotechnol. Bioeng. 43, 1001-1009.

Holan, Z. R., Volesky, B. and Prasetyo, I. (1993). Biotechnol. Bioeng. 41, 819-825.

Jang, L. K., Nguyen, D. and Geesey, G. G. (1995). Wat. Res. 29, 315-321.

Jang, L. K., Nguyen, D. and Geesey, G. G. (1995). Wat. Res. 29, 307-313.

Jansson-Charrier, M., Guibal E., Roussy, J., Surjous, R. and LeCloirec, P. (1996). Wat. Sci. Tech. 34, 169-177.

Jeffers, T.H. and Corwin, R.R. (1993). Waste water remediation using immobilized biological extractants. In: Biohydrometallurgical Technologies, Proceedings of the International Biohydrometallurgy Symposium, A.E. Torma, M.L. Apel and C.L. Brierley, eds. Vol. 2, pp. 1-14, Warrendale, PA: The Minerals, Metals and Materials Society.

Jeffers, T.H., Ferguson, C.R. and Bennet, P. (1991). Biosorption of metal contaminants from acidic mine water. In: Mineral Bioprocessing, R.W. Smith and M. Misra, eds. pp. 289-299, The Minerals, Metals, and Materials Society.

Jha, I.N., Iyengar, L. and Prabhakara Rao, A.V.S. (1988). J. Environ. Eng. 114, 962-974. Klein, G., Tondeur, D. and Vermeulen, T. (1967). Ind. Eng. Chem. Fundam. 6, 339-350. Kratochvil, D., Fourest, E. and Volesky, B. (1995). Biotechnol. Lett. 17, 777-782.

Kratochvil, D. and Volesky, B. (1997). Water Res. (submitted),

Kratochvil, D. and Volesky, B. (1997). Trans. Inst. Min. Metall. Section C,

Kratochvil, D. and Volesky, B. (1997). Removal of heavy metals by a new biosorbent. In: Biotechnology and the Mining Environment, Proceedings of the 13th 
Biominet Meeting, L. Lortie, P. Bedard and W.D. Gould, eds. vol. SP 97-1, pp. 41-59, Ottawa, Ontario, Canada K1A 0G1: CANMET, Nat. Res. Canada.

Kratochvil, D. and Volesky, B. (1998). Wat. Res. (submitted),

Kratochvil, D. and Volesky, B. (1998). J. Envir. Eng. (submitted),

Kratochvil, D., Volesky, B. and Demopoulos, G. (1997). Wat. Res. (in press).

Langmuir, I. (1918). J. Am. Chem. Soc. 40, 1361-1403.

Macaskie, L. E. and Dean, A. C. R. (1990). Metal-sequestering biochemicals. In: Biosorption of Heavy Metals, B. Volesky, ed. pp. 199-248, Boca Raton, FL: CRC Press, Inc.

Matheickal, J.T. and Yu, Q. (1996). Wat. Sci. Technol. 34, 1-7.

Mahan, C. A. and Holcombe, J. A. (1992). Anal. Chem. 64, 1933-1939.

Milot, C., Guibal, E., Roussy, J. and LeCloirec, P. (1997). Chitosan gel beads as a new biosorbent for molybdate removal. In: Abstr. 3rd Int. Conf. Miner. Bioprocess. Biorecov./Bioremed. Big Sky, MT, NY: Eng. Found.

Muraleedharan, T.R., Philip L., Iyengar L. and Venkobachar, C. (1994). Biores. Technol. 49, 179-186.

Muraleedharan, T.R. and Venkobachar, C. (1990). Biotechnol. Bioeng. 35, 320-325.

Muzzarelli, R.A.A. (1973). Natural Chelating Polymers, Toronto, Ont.: Pergamon Press.

Percival, E. and McDowell, R. H. (1967). Chemistry and Enzymology of Marine Algal Polysaccharides, London, U.K.: Academic Press.

Schiewer, S. (1996). PhD Thesis, McGill University, Montreal, Canada.

Schiewer, S. and Volesky, B. (1995). Environ. Sci. Technol. 29, 3049-3058.

Schiewer, S. and Volesky, B. (1996). Environ. Sci. Technol. 30, 2921-2927.

Schiewer, S. and Volesky, B. (1997). Environ. Sci. Technol. (submitted).

Schiewer, S. and Volesky, B. (1997). Environ. Sci. Technol. (in press).

Selke, W. A. (1956). Mass transfer and equilibria. In: Ion Exchange Technology, J. Schubert and F.C. Nachod, eds. pp. 53-62, NY: Acad. Press.

Shallcross, M., Herrmann, C.C. and McCoy, B.J. (1988). Chem. Eng. Sci.. 43, 279-288.

Sharma, D.C. and Forster, C.F. (1993). Water Res. 27, 1201-1208.

Spinti, M., Zhuang, H. and Trujillo, E.M. (1995). Water Environ. Res. 67, 943-952.

Tan, H.K.S. and Spinner, I.H. (1994). Can. J. Chem. Eng. 72, 330-341.

Tondeur, D. and Klein, G. (1967). Ind. Eng. Chem. Fundam. 6, 351-361.

Treen-Sears, M.E., Volesky, B. and Neufeld, R.J. (1984). Biotechnol. Bioeng. 26, 13231329.

Trujillo, E.M., Jeffers, T.H., Ferguson, C. and Stevenson, H.Q. (1991). Environ. Sci. Technol. 25, 1559-1565.

Tsezos, M. (1980). Montreal, Canada,

Tsezos, M. and Volesky, B. (1981). Biotechnol.Bioeng. 23, 583-604.

Vermeulen, T., Klein, G. and Heister, N.K. (1973). Adsorption and ion exchange. In: Chemical Engineers' Handbook, 5th ed., R.H. Perry and C.H. Chilton, eds. vol. pp. Ch.16, NY: McGraw-Hill.

Volesky, B. and Holan, Z. R. (1995). Biotechnol. Prog. 11, 235-250.

Volesky, B. and Prasetyo, I. (1994). Biotechnol. Bioeng. 43, 1010-1015.

Votapek, V., Marval, E. and Stamberg, K. (1978). U.S. Patent 4067821.

Yang, J. and Volesky, B. (1996). J. Chem. Technol. Biotechnol. 66, 355-364. 
Figure 1: Metal biosorption equilibrium uptake as a function of solution $\mathrm{pH}$ :

While higher $\mathrm{pH}$ favours metal binding, lower $\mathrm{pH}$ could be used for releasing the deposited metal back into solution implying that regeneration of biosorbent material could be accomplished by simple acid wash.

$\mathrm{COOH}$ carboxyl groups seem to play an important role in biosorption.

Figure 2: Biosorption equilibrium isotherm plots (metal) uptake $(q)$ against the residual (metal) concentration remaining in solution:

When different biosorbents are being compared, biosorption performance in terms of uptake $\left(\mathrm{q}_{10}, \mathrm{q}_{200}\right)$ has to be judged at the same (selected: e.g. 10 and/or $200 \mathrm{mg} \mathrm{l}^{-1}$ ) equilibrium (final) metal concentration. $\mathrm{q}_{\max }$ comparison is also useful.

Figure 3: a) The equilibrium biosorption isotherm for a binary system becomes a 3-D surface plot, usually smoothed through data points (example: Sargassum Cd+Fe biosorption data: $\mathbf{o})^{51}$.

b) The effect of Fe on the Cd uptake is derived by 'cutting' the isotherm surface by Fe ‘iso-concentration' planes and plotting the resulting curves.

c) The summary of the Fe effect on the Cd uptake at different $\mathrm{Cd}$ concentrations can be expressed from b). At low Cd levels Fe affects the Cd uptake very strongly, not so at higher Cd concentrations.

(Equilibrium concentrations in $\mathrm{mM}=$ millimoles $\mathrm{l}^{-1}$ )

Figure 4: Ion exchange equilibrium isotherm becomes relevant when two ions exchange at one active binding site. A favourable isotherm features a higher fraction of the bound ion A than the A fraction remaining in the liquid phase.

Figure 5: Biosorption in a flow-through packed-bed biosorption column:

When the metal 'breaks through' and becomes detectable at the column exit at a preset (or given) concentration, the useful life of the column is over (the column service time). However, at that time the column is still not completely used up (saturated) because of the unsaturated transfer zone inside which should be minimized. 
Figure 6: Breakthrough curves obtained from operation of biosorption columns:

Unfavourable breakthrough curve is flat and trailing indicating a wasteful long transfer zone inside the column.

Favourable breakthrough curve is steep and sharp marking effective utilization of the biosorbent material inside the column.

Figure 7: $\quad$ Examples of exit metal concentration overshoots in operation of biosorption columns when two (or more) metals are being sorbed. The overshooting depends on the affinities of the individual metals to the biosorbent. An arbitrary critical breakthrough metal exit concentration ratio 0.05 was chosen for the example:

a) The biosorption overshoot shortens the operating life span of the column. Metal 2 breakthrough (at $t_{\text {over }}$ ) occurs before that for Metal 1 (at $t_{B}>>t_{\text {over }}$ ). The column operation may have to be terminated at time $t_{\text {over }}$.

b) The biosorption overshoot does not interfere with the operating life span of the column when $t_{\text {over }}>t_{B}$. The column can be operated all the way until $t_{B}$. 


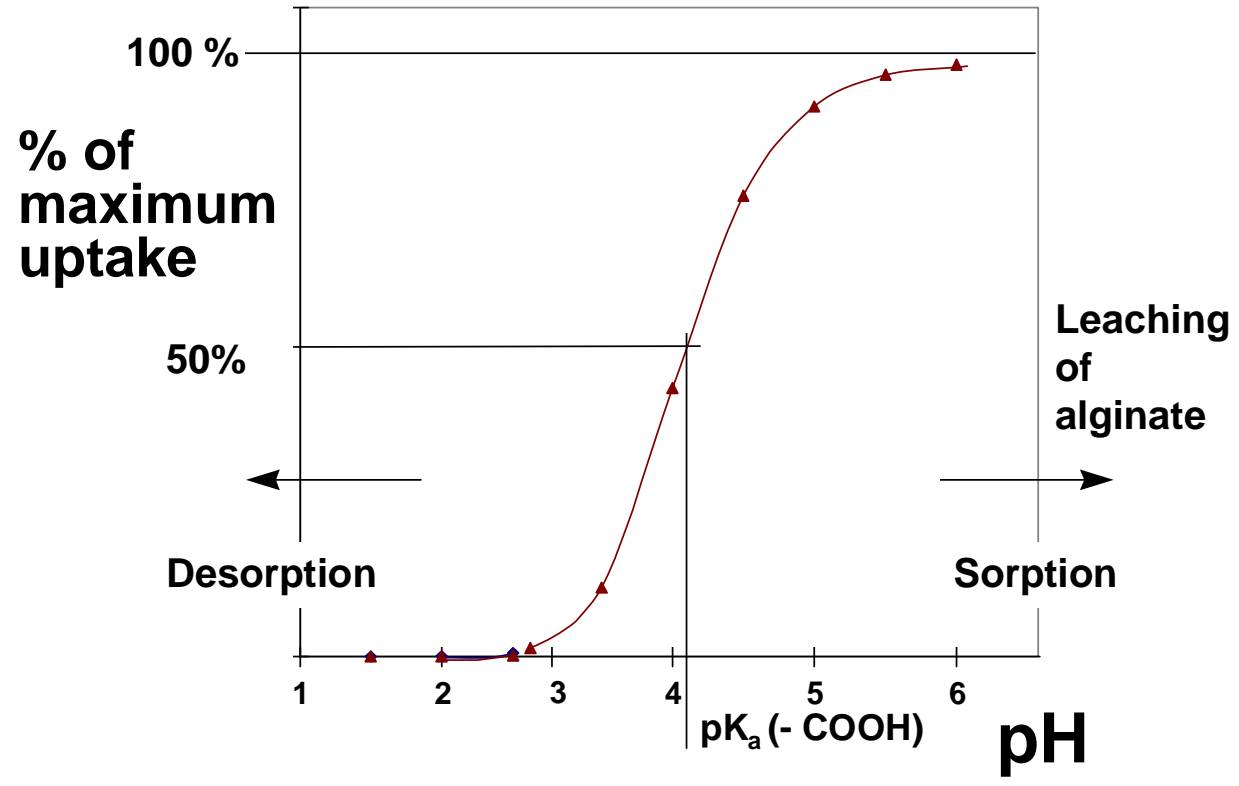

Figure 1 


\section{METAL \\ UPTAKE}

[mg g ${ }^{-1}$ ]

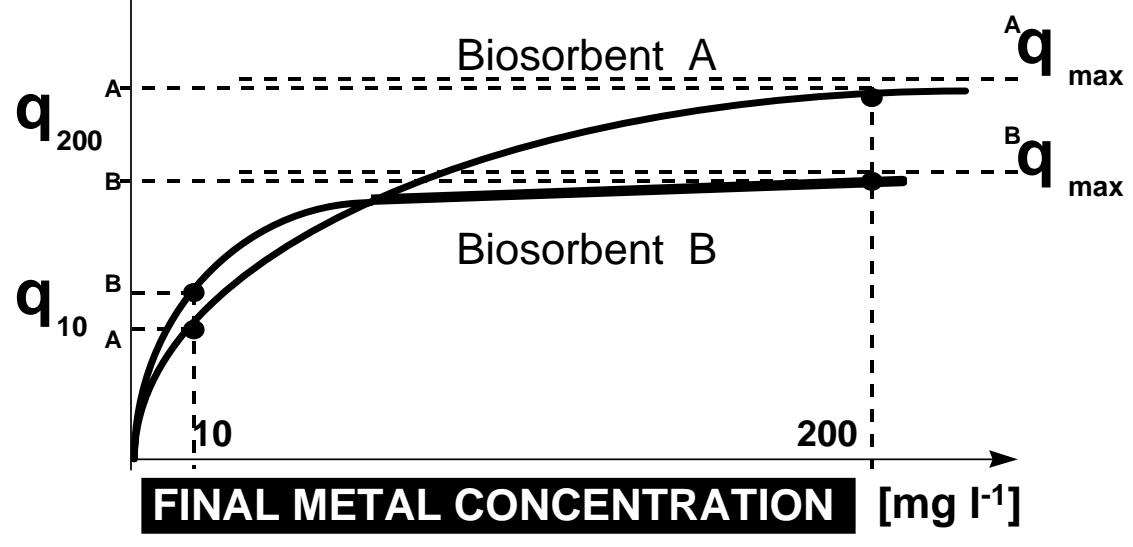

Figure 2 


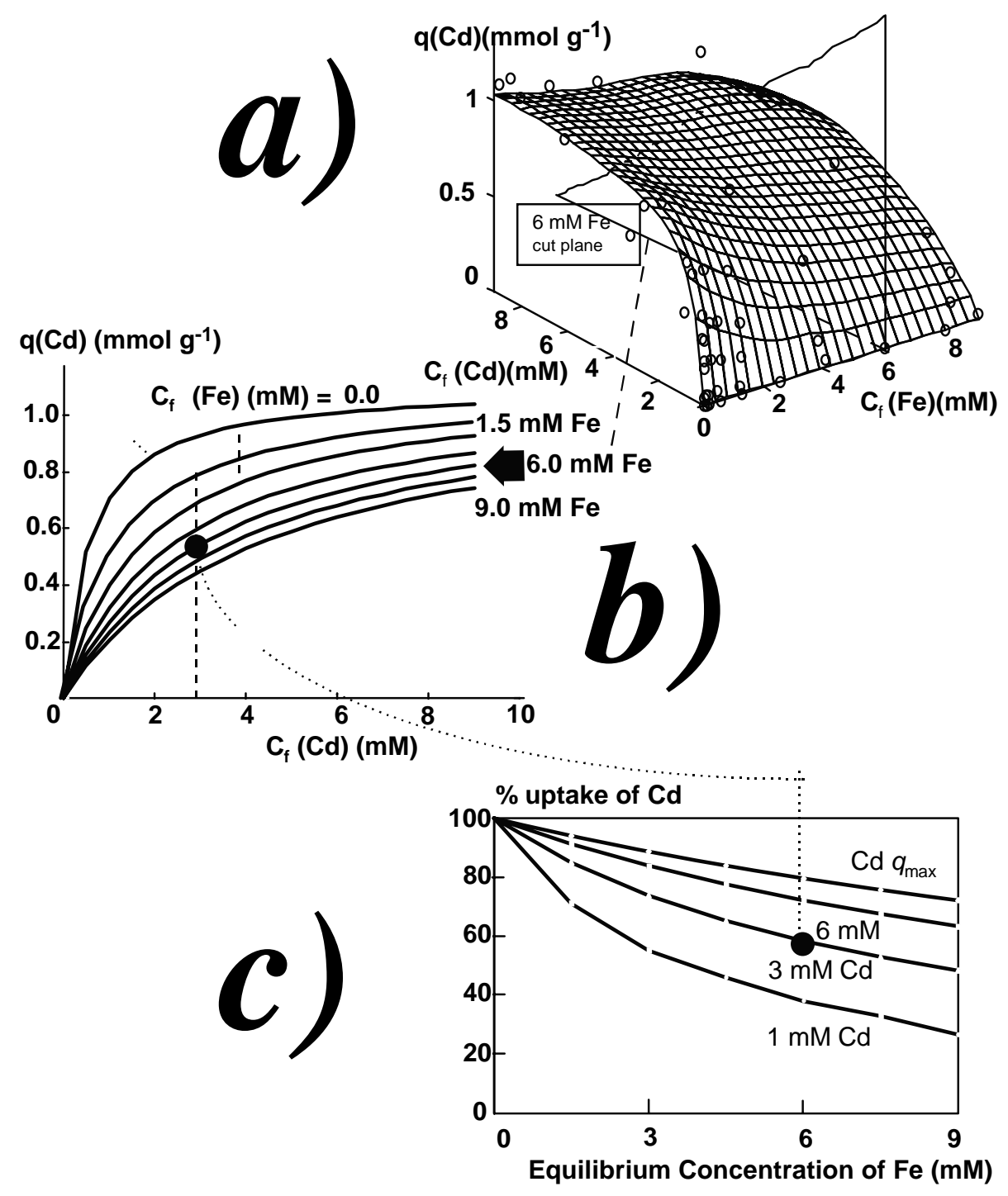

Figure 3 


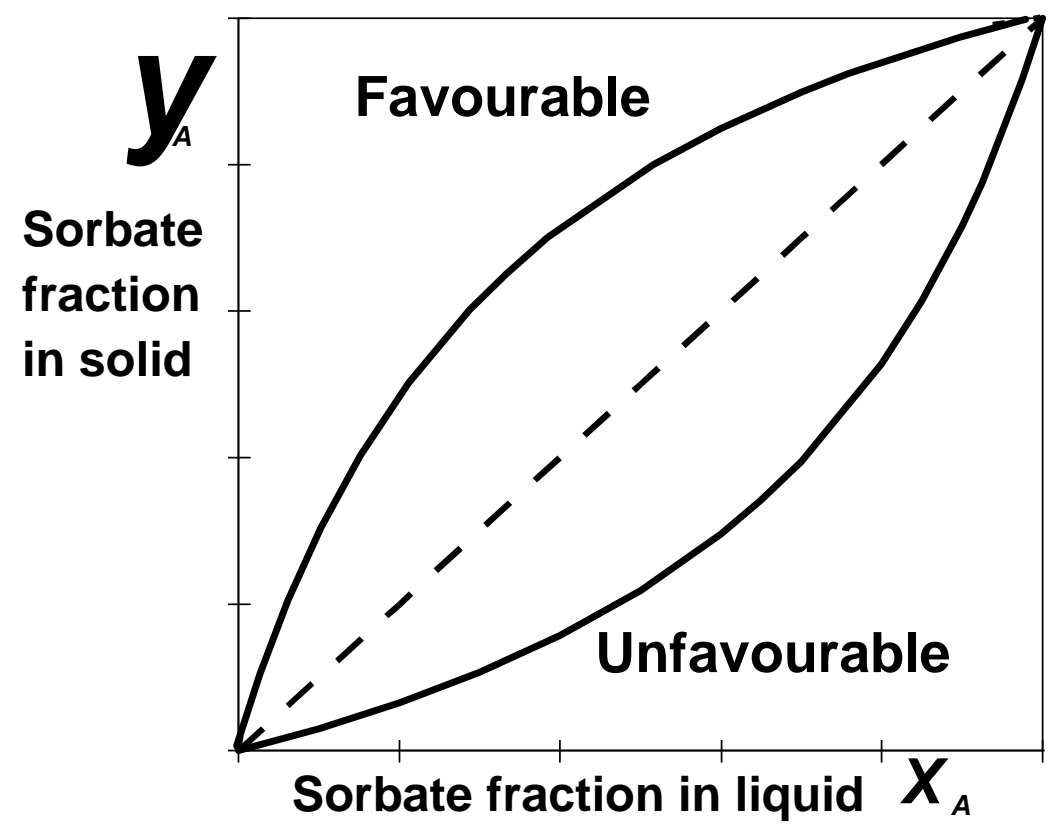

Figure 4 


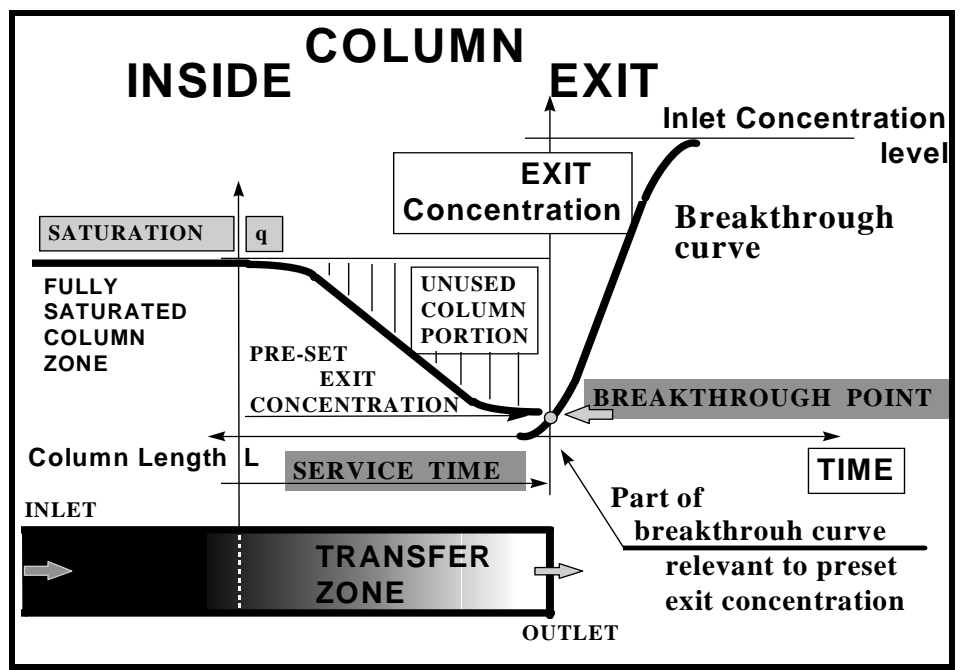

Figure 5 


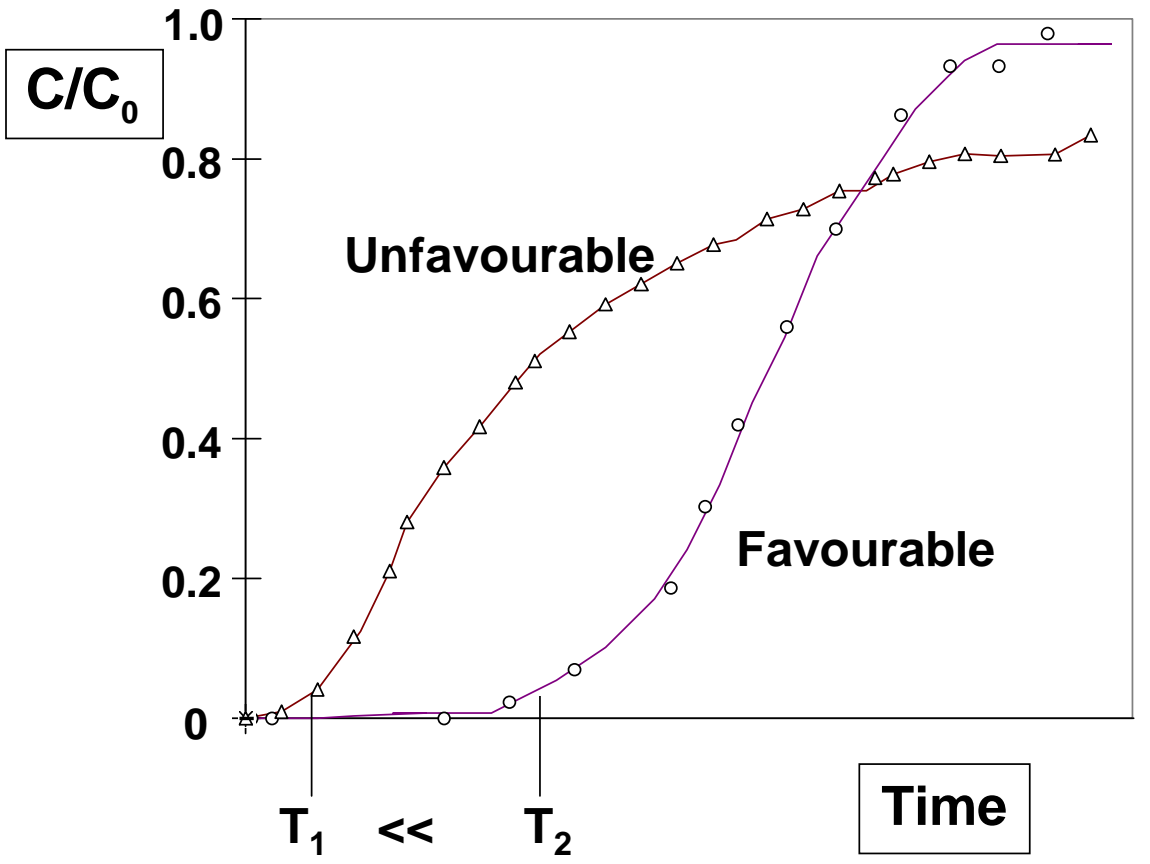

Figure 6 

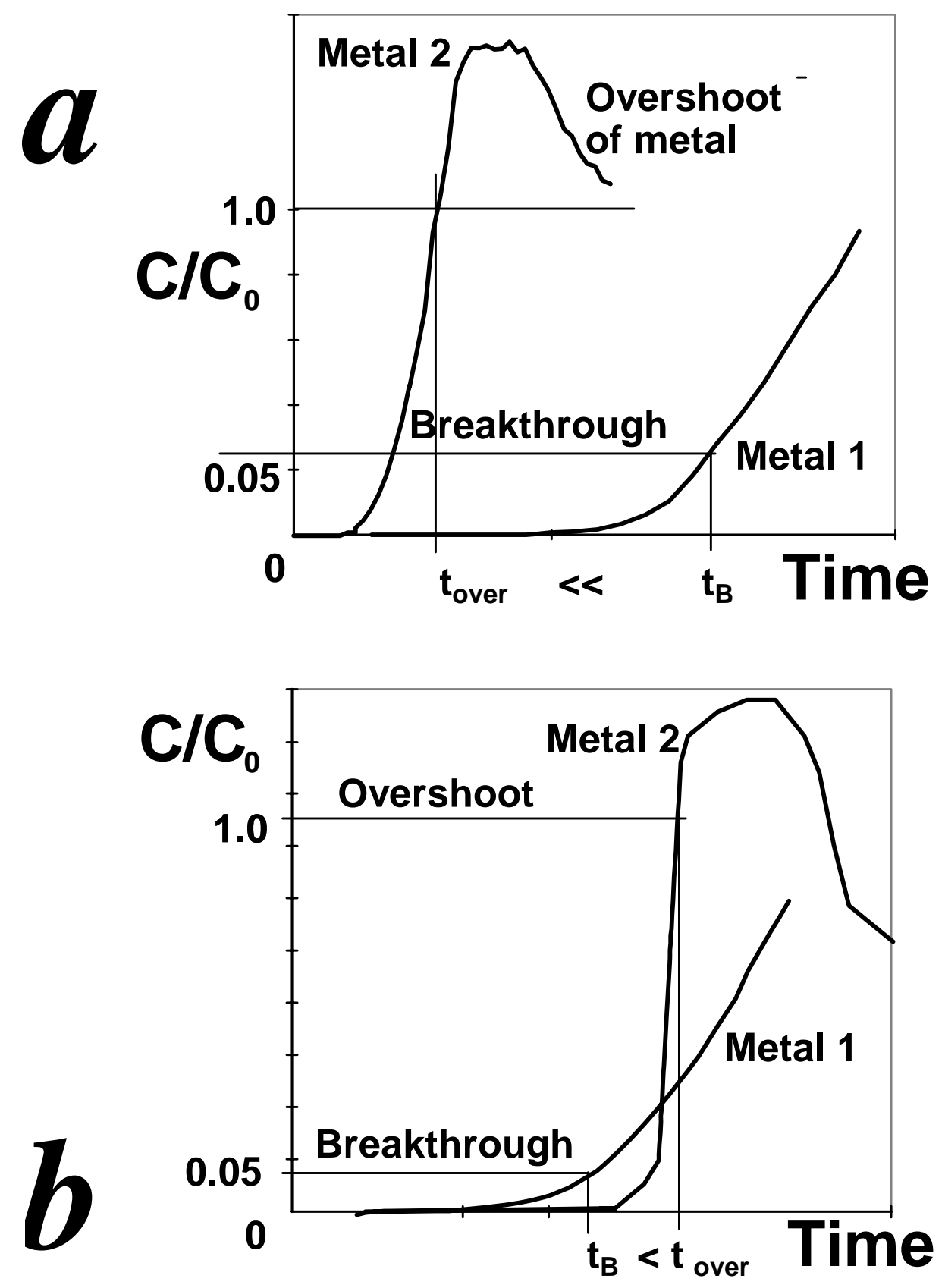

Figure 7 